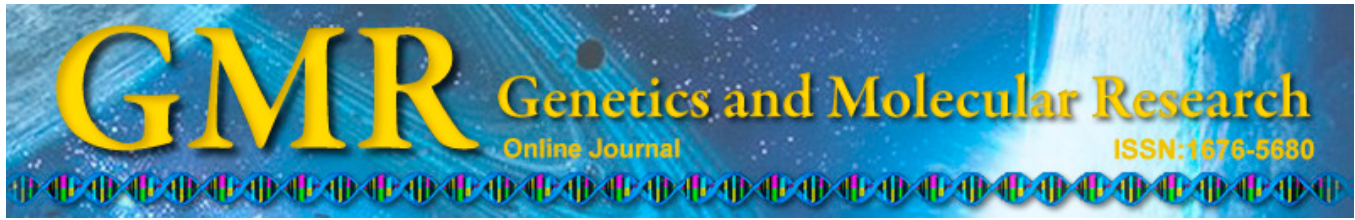

\title{
Interactome analysis and design of inhibitors against selected protein targets of Ser/Thr protein kinase (STPK) signaling pathways in Mycobacterium tuberculosis H37Rv
}

\author{
A.B. Gurung ${ }^{1}$, B.J. Mylliemngap ${ }^{1}$, A. Bhattacharjee ${ }^{1}$, M.A. Ali ${ }^{2}$ and \\ F.M.A. Al-Hemaid ${ }^{2}$ \\ ${ }^{1}$ Department of Biotechnology and Bioinformatics, North Eastern Hill University, \\ Shillong, Meghalaya, India \\ ${ }^{2}$ Department of Botany and Microbiology, College of Science, \\ King Saud University, Riyadh, Saudi Arabia \\ Corresponding authors: M.A. Ali / A. Bhattacharjee \\ E-mail: alimohammad@ksu.edu.sa / atanubioinfo@gmail.com
}

Genet. Mol. Res. 14 (3): 10390-10403 (2015)

Received March 26, 2015

Accepted May 18, 2015

Published September 1, 2015

DOI http://dx.doi.org/10.4238/2015.September.1.6

\begin{abstract}
Tuberculosis continues to be a major cause of mortality worldwide despite significant advances in chemotherapy and development of the BCG vaccine. Although curable, the tuberculosis treatment period (6-9 months) presents many concerns, including patient noncompliance and the development of drug toxicity and drug resistance. This study aimed to understand the protein-protein interactions of key proteins involved in the Mycobacterium tuberculosis STPK signal transduction pathway (such as PknB, PknE, and PstP); in addition, we attempted to identify promising leads for the inhibition of protein-protein interactions. Interactome analyses revealed the interactions of these protein targets with several other proteins, including PknG and PbpA. Drug-like candidates were screened based on Lipinski's rule of five and the absorption digestion metabolism
\end{abstract}


excretion toxicity. Molecular docking of the target proteins with the selected ligands identified cryptolepine $\mathrm{HCl}$ to be a common molecule interacting with all protein targets (with a good docking score). The generation of a pharmacophore model for cryptolepine $\mathrm{HCl}$ revealed three pharmacophoric regions: aromatic hydrocarbon, hydrogen bond acceptor, and hydrogen bond donor, which play important roles in its interaction with the protein targets. Therefore, cryptolepine $\mathrm{HCl}$ appears to be a promising drug candidate for further optimization and validation against $M$. tuberculosis.

Key words: Ser/Thr protein kinase; Pharmacophore modeling; Docking; Interactome; Signal transduction

\section{INTRODUCTION}

Mycobacterium tuberculosis is the causative agent of tuberculosis (TB), which is the leading cause of death worldwide. Recent estimates have suggested that a third of the population worldwide asymptomatically harbors a dormant or latent form of M. tuberculosis, with a lifelong risk of disease reactivation (Koul et al., 2011). Despite tuberculosis being curable, two developments regarding the recent TB resurgence are of great concern: co-infection with HIV-AIDS (Tufariello et al., 2003) and the emergence of multi-drug resistant strains of $M$. tuberculosis (Zvi et al., 2008). The latter problem can be attributed to the lengthy treatment period and patient noncompliance. Most of the currently available TB drugs are ineffective against persistent bacteria (Zhang, 2005); in addition, a comprehensive vaccine for TB also remains elusive (Gupta et al., 2012). Such problems warrant the need for new anti-TB drugs that could help to eliminate multidrug-resistant strains of M. tuberculosis.

Protein phosphorylation is the principal means by which environmental signals are converted to appropriate cellular responses in both prokaryotes and eukaryotes. The two-component systems (TCS), consisting of histidine sensor kinase/response regulator partner proteins play a key role in this process in bacteria, with phosphorylation occurring at the histidine/aspartic acid residues. In contrast, the Ser/Thr protein kinases (STPKs) and phosphoprotein phosphatases constitute the mainstay of signal transduction pathways in eukaryotes. Mycobacteria are characterized by the presence of both classes of signal transduction systems, that is, the TCS and eukaryotic-like STPK proteins (Tyagi and Sharma, 2004). The M. tuberculosis genome includes 11 STPK genes ( $p k n A$ to $p k n L$ ) (Cole et al., 1998), and their domain organization indicates that only two enzymes (PknG and PknK) are soluble proteins. All other mycobacterial STPKs are predicted to be transmembrane (receptor-like) proteins (Av-Gay and Everett, 2000), with their $\mathrm{N}$-terminal kinase domain connected through a single transmembrane helix to one or more Cterminal domains, which presumably serve as signal sensors. The $M$. tuberculosis genome also includes three genes ( $p s t P, p t p A$, and $p t p B$ ) encoding eukaryotic-like protein phosphatases in addition to STPKs. PstP is a metalloenzyme that belongs to the PPM family of Ser/Thr protein phosphatases, which is known to dephosphorylate various mycobacterial STPKs and their substrates (Boitel et al., 2003; Chopra et al., 2003; Durán et al., 2005).

The M. tuberculosis serine/threonine protein kinases are promising drug targets because of their significant role in serine/threonine phosphorylation in M. tuberculosis. PknA and PknB are essential kinases regulating M. tuberculosis (Sassetti et al., 2003; Kang et al., 
2005; Fernandez et al., 2006), while PknG plays an important role in bacterial survival within the macrophage either via its role in glutamate metabolism (Cowley et al., 2004) or via the modulation of host cell trafficking pathways (Walburger et al., 2004).

Protein-protein interactions are important mechanisms that drive many physiological processes in the cell; these have also been implicated in the pathogenesis of diseases such as Alzheimer's disease, cervical cancer, bacterial infection, and prion diseases (Cohen and Prusiner, 1998; Selkoe, 1998; Loregian et al., 2002). Because of the wide diversity of proteinprotein interactions, all possible interacting partners of a given protein must be thoroughly understood and identified. The establishment of protein interaction networks using a bioinformatics approach plays a crucial role in the drug discovery process, especially when proteinprotein interactions are implicated in the development of diseases. Rational drug design has largely benefited from the introduction of the concept of 'pharmacophore', introduced in 1909 by Ehrlich (1909); since then, approaches utilizing pharmacophores have been widely used in virtual screening and drug design. A pharmacophore is a molecular framework that carries the essential features responsible for the biological activity of the drug (Ehrlich, 1909). A pharmacophore model can be ligand-based (extracting common chemical features from a set of bioactive ligands) or structure-based (studying the protein-ligand interactions).

The aim of this study is to understand the protein-protein interactions of key proteins such as PknB, PknE, and PstP, involved in the M. tuberculosis STPK signal transduction pathway and to identify the novel leads that can inhibit the protein-protein interactions. The target proteins were chosen based on their involvement in the phosphorylation and de-phosphorylation mechanisms required for signal transduction; therefore, targeting these proteins could help inhibit protein-protein interaction and inhibit the growth of M. tuberculosis within the cells.

\section{MATERIAL AND METHODS}

\section{Retrieval of target protein sequences}

The primary sequences of the target proteins protein kinase $\mathrm{B}(\mathrm{PknB})$, protein kinase $\mathrm{E}(\mathrm{PknE})$, and serine/threonine phosphatase (PstP) were retrieved from the UniProt database (www.uniprot.org).

\section{Prediction of functional protein partners}

Functional protein partners for the three protein targets PknB, PknE, and PstP were predicted using STRING 9.1 (Szklarczyk et al., 2011). STRING is a freely accessible database consisting of known and predicted protein-protein interactions, which quantitatively integrates the interaction data from several sources for a large number of organisms.

\section{Determination of the essentiality of the selected target proteins and their functional partners}

The basic local alignment search tool (BLAST) was used to determine the essentiality of the target proteins and their functional partners in the database of essential genes (DEG) (Zhang et al., 2004). Essential genes are indispensable for the survival of an organism and are therefore considered to form the foundation of life. DEG hosts the records of currently avail- 
able essential genes among a wide range of organisms.

\section{Determination of the homology for PknB, PknE, and PstP in humans using BLAST}

The target proteins PknB, PknE, and PstP and their functional partners PknG and PbpA were subjected to a National Center for Biotechnology Information BLAST search against Homo sapiens, in order to identify the possible homology of these target proteins with humans.

\section{Retrieval of the three-dimensional structures of the proteins and structural analysis}

The three-dimensional structures of the target proteins were downloaded from protein data bank (PDB) (www.rcsb.org). The Procheck tool (http://nihserver.mbi.ucla.edu/SAVES/) was used to analyze the stereochemistry of the protein structures of the target proteins, via the analysis of residue-by-residue geometry.

\section{Preparation of ligands}

The three-dimensional structures of antimicrobial compounds were retrieved from the PubChem database (https://pubchem.ncbi.nlm.nih.gov/) in the 3D SDF format; those compounds whose structures were not available in the PubChem database were modeled using the ChemSketch tool.

\section{Screening of ligands}

The ligands were screened with the Molinspiration tool (http://www.molinspiration. com/) by applying the rule of five; the absorption digestion metabolism excretion (ADME) toxicity analysis of the filtered compounds was performed using the Osiris tool. Molinspiration (http://www.organic-chemistry.org/prog/peo/) predicts the bioactivity of the compounds based on the following criteria: a) milogP (octanol-water partition co-efficient) $\leq 5$, b) topology polar surface area $($ TPSA $) \leq 140$, c) number of atoms $($ nATOMS $)=20-70$, d) molecular weight $\leq 500$, e) electron acceptor $(\mathrm{nON}) \leq 10, \mathrm{f})$ electron donor $(\mathrm{nOHN}) \leq 5$, g) number of violations (nviolation) $=0, \mathrm{~h}$ ) number of rotatable bonds $(\mathrm{nRotB}) \leq 10$. Osiris predicts the drug likeness and toxicity (including mutagenicity, irritancy, and reproductive effect), based on the following criterion: a) lipophilicity $(\operatorname{cog} P) \leq 5$, b) solubility $>-4$, c) drug likeliness $\geq 0$, d) drug score $\geq 0.5$; green color indicates "no risk", orange color indicates "medium risk", and red color indicates "high risk".

\section{Prediction of active site residues}

The binding site residues were predicted for two protein targets PbpA and PstP using CastP, while the binding sites for the other proteins (PknG, PknE, and PknB) were defined from the ligand already bound to the crystal structures.

\section{Molecular docking}

Molecular docking was performed using the GOLD software (v.5.2). All water mol- 
ecules and ligands were extracted from the protein structures. The binding sites were defined for each protein. The binding sites of PknB, PknG, and PknE were defined at approximately $6 \AA$ from the bound inhibitor and predicted for PbpA and PstP using CastP. Twenty genetic algorithm (GA) runs were performed for each compound. The selection pressure for each GA run was set to 1.1; one hundred thousand GA operations were performed on a set of five islands, with a population size of 100 individuals. The operator weights for crossovers, mutations, and migrations were set to the default values. The protein-ligand interactions were further studied using the LigPlot tool (http://www.ebi.ac.uk/pdbsum/). The LIGPLOT program automatically generates schematic 2-D representations of protein-ligand complexes from a standard protein data bank file input.

\section{Pharmacophore modeling}

A pharmacophore model defines the minimum necessary structural characteristics that a molecule must possess in order to bind to the target. The best twelve docked ligands were used to build a pharmacophore model using the V-life MDS software v3. The ligands were loaded, and ligand 10 was selected as the reference ligand, as it was observed to superimpose well with all 11 ligands.

\section{RESULTS AND DISCUSSION}

The interactome analyses predicted the interaction of the three protein targets $(\mathrm{PknB}$, PknE, and PstP) with several other proteins (Figure 1), with high confidence scores (Table 1). The common predicted functional partner proteins were PknG and PbpA. The selected protein targets and their predicted functional partners were predicted to be important for the survival of the organism, based on the percentage of identity of these proteins against those of the prokaryotic organisms of the DEG database (Table 2). The selected protein targets showed no significant homology with their human counterparts (Table 3), indicating that the inhibitors designed for the targets would show less cross-reactivity in vivo, possibly resulting in lesser side-effects. Binding site residues were predicted for two protein targets PbpA and PstP (Figure 2). The binding sites for the other targets were retrieved from the ligands bound to the crystal structures. The three dimensional structures of the target proteins were considered to be stereochemically good as a majority of the residues existed within the most favored regions (Figure 3, Table 4), which signified a lower number of steric clashes between the backbone and the side chains in the protein structures. Twenty-five of the 253 antimicrobial compounds (142 natural and 111 synthetic compounds) were selected for molecular docking studies based on the drug-likeness and ADME properties (Tables 5-7).

Molecular docking of the target proteins with the 25 ligands suggested that the ligand 7 to be the common ligand interacting with all protein targets $(\mathrm{PknB}, \mathrm{PknE}$, PstP, PknG, and PbpA) with good docking scores $(45.1423,40.7455,49.6259,54.6775$, and 63.8415, respectively; Table 8). Ligand 7 mostly formed hydrophobic interactions with $\mathrm{PknB}$, and hydrogen bonds and hydrophobic interactions with the remaining protein targets (Figure 4). A pharmacophoric analysis of Ligand 7 (Figures 5-6) revealed that the nitrogen $(\mathrm{N})$ atom of the pyrrole ring acted as pharmacophoric atom, where the ligand interacted with the target proteins. In addition, three pharmacophoric regions, aromatic hydrocarbon (AroC), hydrogen bond acceptor (HAc), and hydrogen bond donor (HDr), were also discovered in this ligand. 


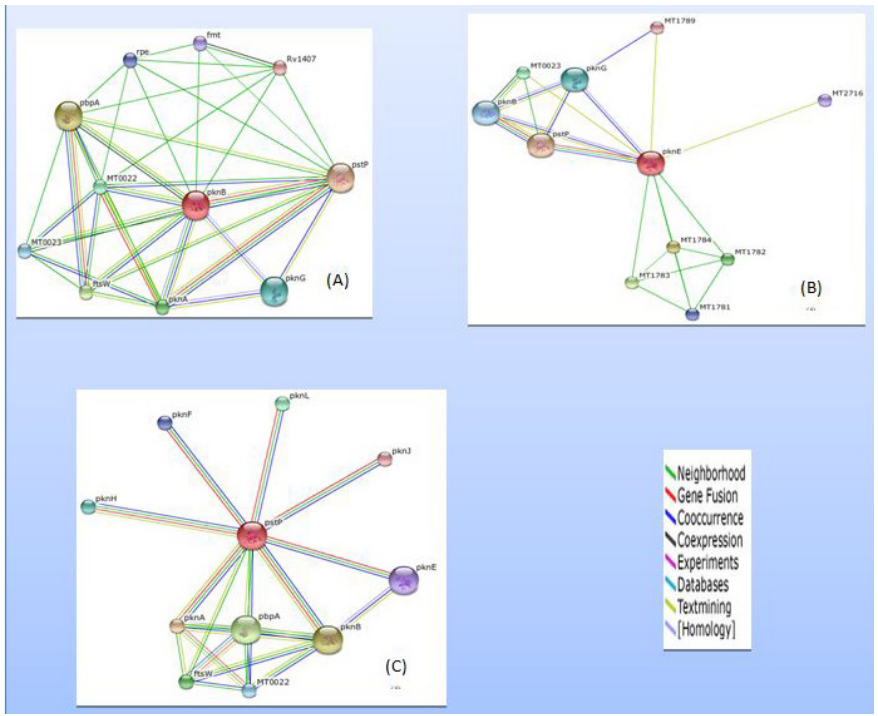

Figure 1. Protein network view for the target proteins-(A) PknB (B) PknE (C) PstP. The central red spheres indicate target proteins interconnected by other spheres which represent predicted functional partners. On the bottom right panel shows color codes for the active String prediction methods.

Table 1. Predicted functional partners of target proteins (PknB, PknE, and PstP) and their string score.

\begin{tabular}{|c|c|c|c|}
\hline S. No. & Protein target & Interacting partners & String score \\
\hline \multirow[t]{10}{*}{1.} & PknB & PstP & 0.998 \\
\hline & & $\mathrm{PbpA}$ & 0.996 \\
\hline & & Ftsw & 0.982 \\
\hline & & MT0023 & 0.978 \\
\hline & & $\operatorname{Rv} 1827$ & 0.972 \\
\hline & & MT0022 & 0.946 \\
\hline & & $\mathrm{GlmU}$ & 0.908 \\
\hline & & PknA & 0.908 \\
\hline & & MT0537 & 0.900 \\
\hline & & EmbR & 0.864 \\
\hline \multirow[t]{10}{*}{2.} & PknE & PstP & 0.972 \\
\hline & & MT0537 & 0.926 \\
\hline & & MT1789 & 0.843 \\
\hline & & MT0023 & 0.843 \\
\hline & & Rv1365c & 0.840 \\
\hline & & EmbR & 0.839 \\
\hline & & PknG & 0.759 \\
\hline & & PbpA & 0.724 \\
\hline & & PknK & 0.614 \\
\hline & & Ag84 & 0.607 \\
\hline \multirow[t]{10}{*}{3.} & PstP & PknB & 0.998 \\
\hline & & PknA & 0.997 \\
\hline & & PbpA & 0.997 \\
\hline & & Ftsw & 0.983 \\
\hline & & PknL & 0.972 \\
\hline & & PknE & 0.972 \\
\hline & & PknF & 0.972 \\
\hline & & PknH & 0.970 \\
\hline & & PknG & 0.940 \\
\hline & & Mt0022 & 0.936 \\
\hline
\end{tabular}

The highlighted rows indicate the common interacting partners PstP and PbpA. 
Table 2. Blast results from Database of Essential Genes (DEG).

\begin{tabular}{lllc}
\hline Proteins & DEG ID & Organism & Identity \\
\hline PknG & DEG10100048 & Mycobacterium tuberculosis $\mathrm{H} 37 \mathrm{Rv}$ & $96 \%$ \\
PknB & DEG10100003 & Mycobacterium tuberculosis $\mathrm{H} 37 \mathrm{Rv}$ & $92 \%$ \\
PknE & DEG10100003 & Mycobacterium tuberculosis $\mathrm{H} 37 \mathrm{Rv}$ & $37 \%$ \\
PstP & DEG10070095 & Streptococcus pneumoniae TIGR4 & $33 \%$ \\
PbpA & DEG10050014 & Haemophilus influenzae Rd KW20 & $25 \%$ \\
\hline
\end{tabular}

Table 3. Blast results (Mycobacterium tuberculosis protein against Human taxid: 9606).

\begin{tabular}{|c|c|c|c|c|c|c|c|}
\hline \multirow[t]{2}{*}{ Proteins } & \multicolumn{7}{|c|}{ BLAST results } \\
\hline & Accession & Description & Max. score & Total score & Query coverage & E value & Max. identity \\
\hline PknB & EAX08908 & $\begin{array}{l}\text { NIMA (never in mitosis gene a)- } \\
\text { related kinase } 3 \text {, isoform CRA_d }\end{array}$ & 117 & 117 & $40 \%$ & $7 \mathrm{E}-28$ & $32 \%$ \\
\hline PknE & ADX95745 & SadB kinase short isoform & 118 & 118 & $38 \%$ & $3 \mathrm{E}-28$ & $31 \%$ \\
\hline PstP & Q86UP3 & Full=Zinc finger homeobox protein 4 & 35.8 & 35.8 & $11 \%$ & 0.55 & $29 \%$ \\
\hline PknG & 3BQR_A & $\begin{array}{l}\text { Chain A, Crystal Structure Of Human } \\
\text { Death Associated Protein Kinase3 (Dapk3) }\end{array}$ & 82 & 82 & $27 \%$ & $4 \mathrm{E}-16$ & $30 \%$ \\
\hline
\end{tabular}

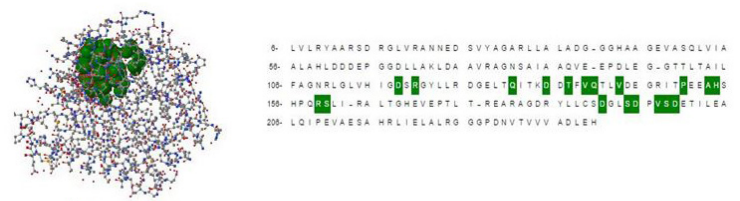

(A)

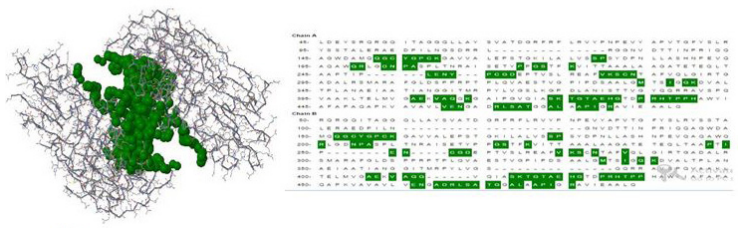

(B)

Figure 2. CASTp result showing active site residues of the protein $\mathrm{PstP}(\mathbf{A})$ and $\mathrm{PbpA}(\mathbf{B})$ in green.

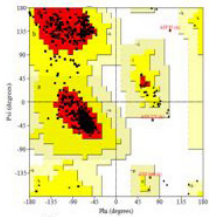

(A)

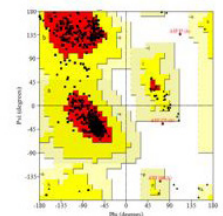

(D)

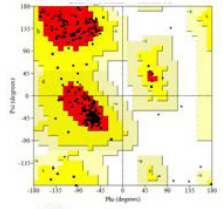

(B)

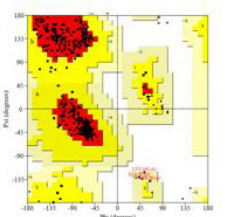

(E)

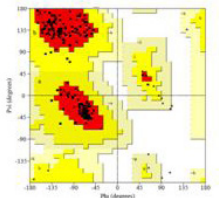

(C)

Figure 3. Ramachandran plot for target proteins $\operatorname{PknB}(\mathbf{A}), \operatorname{PknE}(\mathbf{B}), \operatorname{PstP}(\mathbf{C}), \operatorname{PknG}(\mathbf{D})$, and $\operatorname{PbpA}(\mathbf{E})$.

Genetics and Molecular Research 14 (3): 10390-10403 (2015)

CFUNPEC-RP www.funpecrp.com.br 
Table 4. Summary of Ramachandran plot statistics.

\begin{tabular}{lcccccc}
\hline Proteins & $\begin{array}{c}\text { PDB } \\
\text { entry }\end{array}$ & $\begin{array}{c}\text { Residues in most } \\
\text { favored regions (\%) }\end{array}$ & $\begin{array}{c}\text { Residues in additional } \\
\text { allowed regions (\%) }\end{array}$ & $\begin{array}{c}\text { Residues in generously } \\
\text { allowed regions (\%) }\end{array}$ & $\begin{array}{c}\text { Residues in disallowed } \\
\text { regions (\%) }\end{array}$ & $\begin{array}{c}\text { No. of non-glycine \& } \\
\text { non-proline residues (\%) }\end{array}$ \\
\hline PKnB & lo6y & 92.0 & 7.6 & 0.0 & 0.4 & 100 \\
PknE & 2h34 & 86.7 & 13.3 & 0.0 & 0.0 & 100 \\
PstP & 1txo & 96.0 & 4.0 & 0.0 & 0.0 & 100 \\
PknG & 2pzi & 91.9 & 7.6 & 0.2 & 0.4 & 100 \\
PbpA & 3lo7 & 91.2 & 7.9 & 0.9 & 0.0 & 100 \\
\hline
\end{tabular}

Table 5. Physico-chemical properties of selected compound with Molinspiration.

\begin{tabular}{|c|c|c|c|c|c|c|c|c|c|c|}
\hline Compounds & CID & miLogP & TPSA & natoms & MW & $\mathrm{nON}$ & nOHNH & nviolations & nrotb & vol \\
\hline 1 & - & 2.28 & 77.392 & 24 & 332.352 & 6 & 2 & 0 & 4 & 296.725 \\
\hline 2 & - & 1.385 & 63.604 & 15 & 204.181 & 4 & 1 & 0 & 1 & 172.149 \\
\hline 3 & 2353 & 0.196 & 40.821 & 25 & 336.367 & 5 & 0 & 0 & 2 & 296.302 \\
\hline 4 & 5910 & -0.236 & 44.131 & 15 & 208.261 & 4 & 0 & 0 & 3 & 199.563 \\
\hline 5 & 73201 & 3.132 & 55.767 & 20 & 270.284 & 4 & 1 & 0 & 2 & 239.772 \\
\hline 6 & 73255 & 4.203 & 54.568 & 27 & 368.477 & 5 & 1 & 0 & 4 & 347.713 \\
\hline 7 & 156093 & 3.857 & 17.826 & 18 & 232.286 & 2 & 0 & 0 & 0 & 213.791 \\
\hline 8 & 363272 & 4.27 & 28.263 & 23 & 310.441 & 3 & 1 & 0 & 2 & 303.508 \\
\hline 9 & - & 2.989 & 52.723 & 27 & 356.429 & 5 & 0 & 0 & 7 & 330.106 \\
\hline 10 & - & 1.06 & 123.908 & 22 & 300.274 & 8 & 4 & 0 & 5 & 253.363 \\
\hline 11 & - & 1.643 & 52.723 & 22 & 294.358 & 5 & 0 & 0 & 6 & 275.258 \\
\hline 12 & - & 2.796 & 32.592 & 16 & 233.336 & 2 & 1 & 0 & 1 & 212.305 \\
\hline 13 & - & 0.526 & 54.715 & 12 & 179.204 & 4 & 1 & 0 & 1 & 141.554 \\
\hline 14 & 5391612 & 1.064 & 100.887 & 22 & 299.286 & 7 & 2 & 0 & 6 & 258.73 \\
\hline 15 & - & 0.838 & 119.303 & 34 & 466.473 & 10 & 1 & 0 & 5 & 397.394 \\
\hline 16 & - & 4.05 & 63.083 & 21 & 282.343 & 4 & 1 & 0 & 4 & 267.744 \\
\hline 17 & - & 1.178 & 29.853 & 15 & 201.273 & 3 & 1 & 0 & 5 & 199.471 \\
\hline 18 & - & -0.98 & 109.236 & 20 & 270.252 & 8 & 2 & 0 & 4 & 229.015 \\
\hline 19 & 4472 & 0.377 & 83.115 & 22 & 298.346 & 6 & 3 & 0 & 7 & 276.875 \\
\hline 20 & - & 1.598 & 77.373 & 16 & 261.332 & 7 & 1 & 0 & 2 & 201.513 \\
\hline 21 & - & -1.042 & 108.371 & 21 & 284.279 & 8 & 3 & 0 & 5 & 245.574 \\
\hline 22 & - & 2.819 & 29.098 & 15 & 217.293 & 2 & 1 & 0 & 3 & 194.352 \\
\hline 23 & 4908 & 2.104 & 60.176 & 19 & 259.353 & 4 & 3 & 0 & 6 & 256.91 \\
\hline 24 & 5340 & 0.834 & 85.084 & 16 & 255.324 & 5 & 3 & 0 & 3 & 197.13 \\
\hline 25 & 65720 & -0.564 & 101.392 & 22 & 302.29 & 8 & 2 & 0 & 4 & 256.881 \\
\hline
\end{tabular}

miLogP, octanol-water partition coefficient; TPSA, topology polar surface area; nATOMS, number of atoms; MW, molecular weight; nON, electron acceptor; $\mathrm{nONH}$, electron donor; nviolations, number of violations; nrotb, number of rotable bonds; vol, volume.

Table 6. Toxicity risk of selected compounds as predicted by Osiris. No risk of mutagenic, tumorigenic, irritant and reproductive effectiveness were found in all the cases analyzed.

\begin{tabular}{|c|c|c|c|c|c|c|}
\hline Compounds & CID & cLogP & Solubility & Molecular weight & Drug likeness & Drug-Score \\
\hline 1 & & 2.46 & -2.71 & 332 & 1.7 & 0.8 \\
\hline 2 & & 1.57 & -2.6 & 204 & 0.95 & 0.8 \\
\hline 3 & 2353 & 2.05 & -2.88 & 339 & 2.95 & 0.84 \\
\hline 4 & 5910 & 0.4 & -1.2 & 208 & 1.17 & 0.85 \\
\hline 5 & 73201 & 3 & -3.25 & 270 & 2.05 & 0.8 \\
\hline 6 & 73255 & 2.97 & -3.86 & 368 & 1.8 & 0.7 \\
\hline 7 & 156093 & 2.64 & -3.71 & 232 & 3.75 & 0.83 \\
\hline 8 & 363272 & 4.18 & -3.97 & 310 & 3.69 & 0.69 \\
\hline 9 & & 2.06 & -3.05 & 356 & 2.45 & 0.81 \\
\hline 10 & & 1.09 & -2.83 & 300 & 1.5 & 0.82 \\
\hline 11 & & 0.69 & -1.3 & 294 & 2.6 & 0.91 \\
\hline 12 & & 3.43 & -3.95 & 233 & 0.91 & 0.67 \\
\hline 13 & & 1.96 & -2.11 & 179 & 1.93 & 0.88 \\
\hline 14 & 5391612 & 1.2 & -2.72 & 299 & 6.87 & 0.9 \\
\hline 15 & & -0.16 & -3.16 & 466 & 3.88 & 0.74 \\
\hline 16 & & 0.91 & -2.41 & 261 & 0.95 & 0.8 \\
\hline 17 & & 0.61 & -0.91 & 201 & 1.94 & 0.91 \\
\hline 18 & & -1.16 & -1.46 & 270 & 3.24 & 0.94 \\
\hline 19 & 4472 & 0.47 & -2.42 & 298 & 4.3 & 0.91 \\
\hline 20 & & -2.07 & -1.65 & 261 & 2.19 & 0.91 \\
\hline 21 & & -0.12 & -2.5 & 284 & 4.78 & 0.92 \\
\hline 22 & & 2.71 & -3.1 & 217 & 0.28 & 0.69 \\
\hline 23 & 4908 & 2.56 & -3.1 & 273 & 3.34 & 0.85 \\
\hline 24 & 5340 & 1.13 & -2.76 & 255 & 4.51 & 0.91 \\
\hline 25 & 65720 & -1.12 & -2.93 & 302 & 2.5 & 0.87 \\
\hline
\end{tabular}


Table 7. Final twenty five ligands both Synthetic(S) and Natural(N) compounds selected for molecular docking.

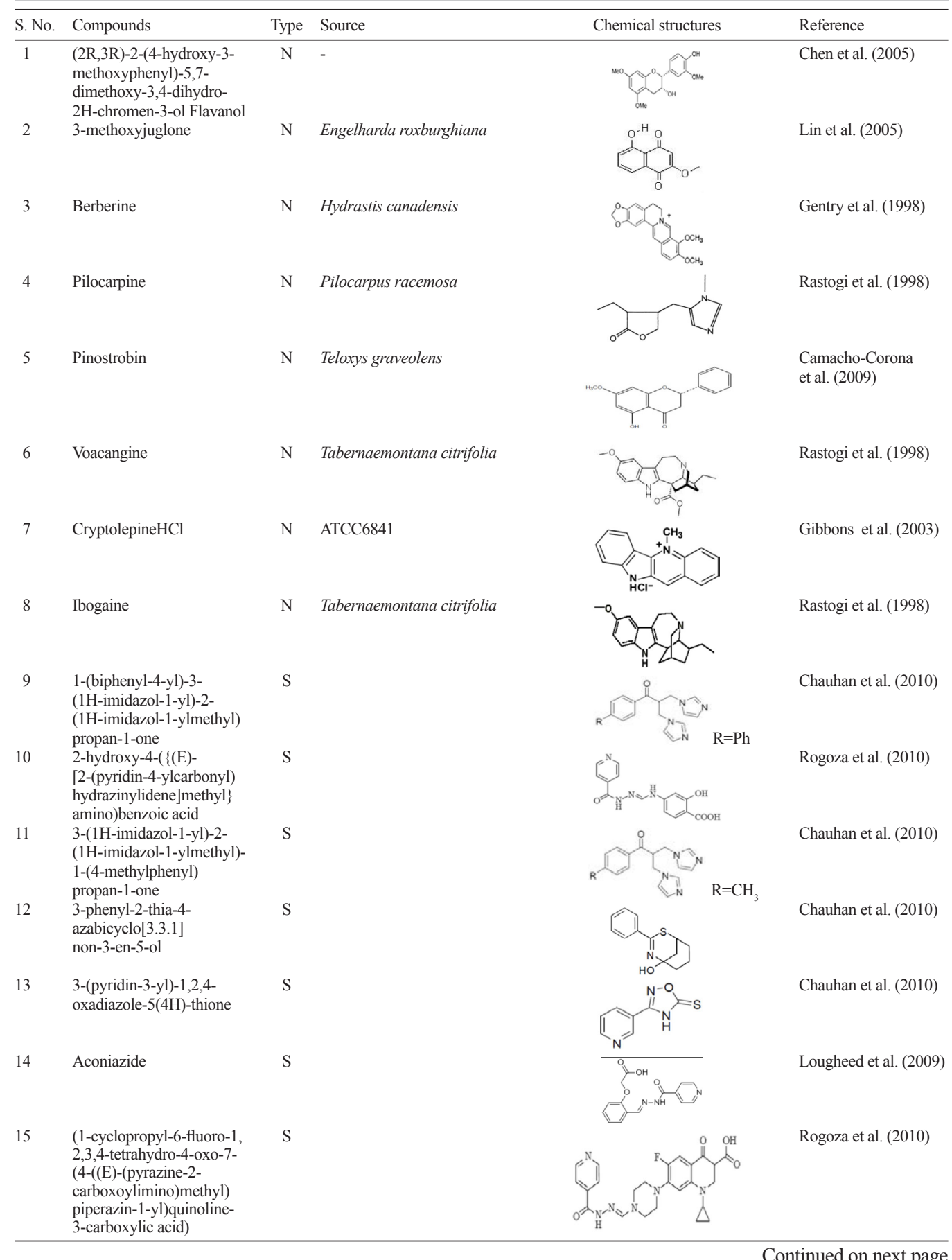




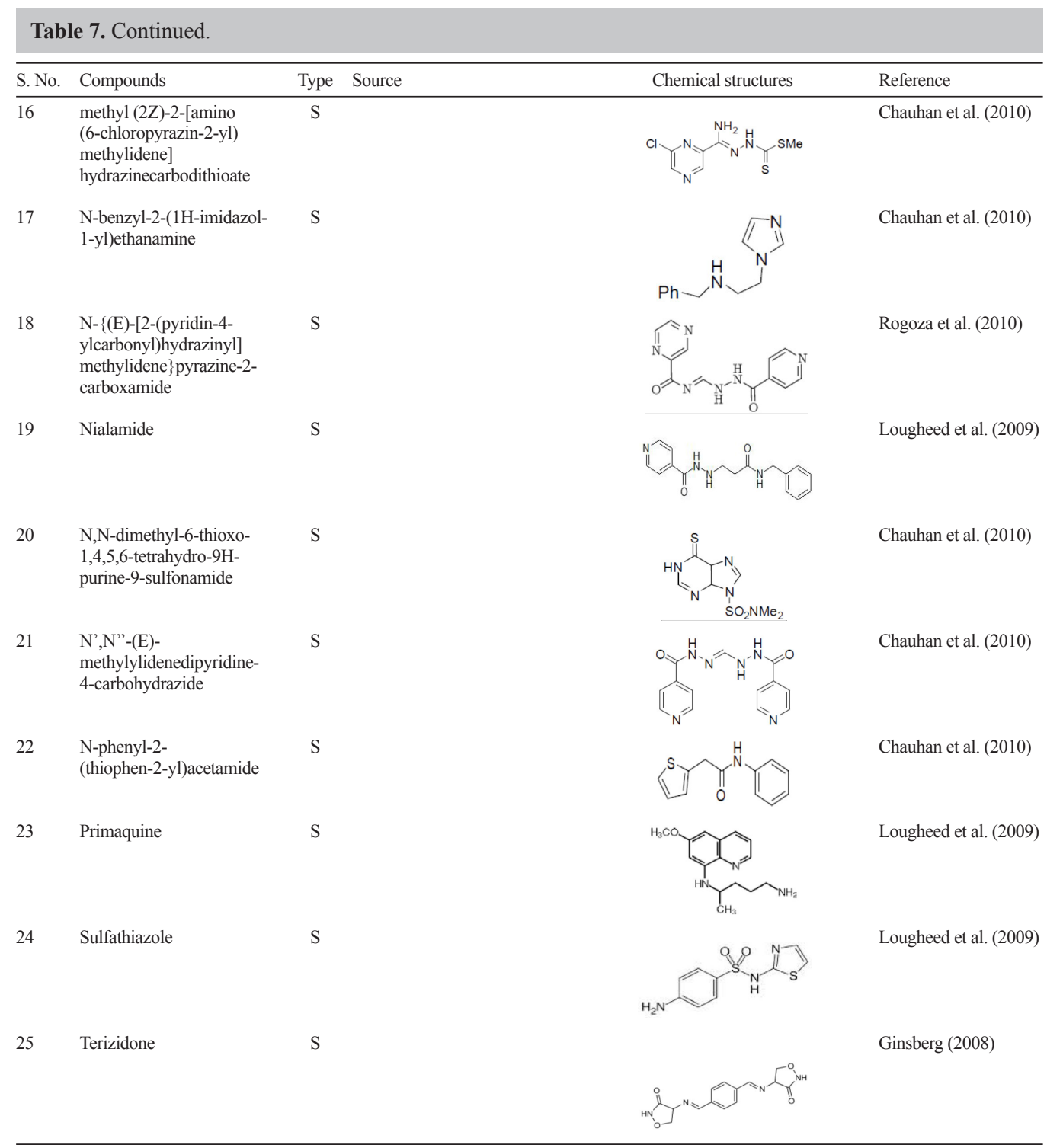

Cryptolepine $\mathrm{HCl}$ (Ligand 7) is an important lead obtained via virtual screening, molecular docking, and pharmacophore analysis. Cryptolepine $\mathrm{HCl}$ is an indoloquinoline alkaloid obtained from the West African medicinal plant Cryptolepis sanguinolenta (Gibbons et al., 2003). The pyrrole ring of this compound can be a scaffold for new derivatives, as deduced from the pharmacophore analysis. Therefore, it could be a promising drug candidate; cryptolepine $\mathrm{HCl}$ must be further optimized to increase its specificity against the target proteins and must be further validated against $M$. tuberculosis by wet laboratory analysis. 
A.B. Gurung et al.

Table 8. Molecular docking result of selected ligands against target proteins.

\begin{tabular}{|c|c|c|c|c|c|c|c|c|c|c|}
\hline \multirow[t]{2}{*}{ Ligands } & \multicolumn{2}{|c|}{ PknB } & \multicolumn{2}{|c|}{ PknE } & \multicolumn{2}{|c|}{ PstP } & \multicolumn{2}{|c|}{ PknG } & \multicolumn{2}{|c|}{$\mathrm{PbpA}$} \\
\hline & $\begin{array}{l}\text { Gold } \\
\text { Score }\end{array}$ & $\begin{array}{c}\text { No. of } \\
\mathrm{H} \text { bonds }\end{array}$ & $\begin{array}{l}\text { Gold } \\
\text { Score }\end{array}$ & $\begin{array}{l}\text { No. of } \\
\mathrm{H} \text { bonds }\end{array}$ & $\begin{array}{l}\text { Gold } \\
\text { Score }\end{array}$ & $\begin{array}{l}\text { No. of } \\
\mathrm{H} \text { bonds }\end{array}$ & $\begin{array}{l}\text { Gold } \\
\text { Score }\end{array}$ & $\begin{array}{l}\text { No. of } \\
\mathrm{H} \text { bonds }\end{array}$ & $\begin{array}{l}\text { Gold } \\
\text { Score }\end{array}$ & $\begin{array}{c}\text { No. of } \\
\mathrm{H} \text { bonds }\end{array}$ \\
\hline 1 & 34.0163 & 3 & 33.6761 & 2 & 42.433 & 3 & 49.1906 & 3 & 47.1717 & 0 \\
\hline 2 & 24.6372 & 3 & 27.2217 & 3 & 32.2145 & 4 & 35.837 & 5 & 42.8637 & 3 \\
\hline 3 & 38.774 & 0 & 37.9058 & 0 & 47.8694 & 0 & 52.586 & 1 & 50.7661 & 0 \\
\hline 4 & 30.1701 & 2 & 24.9583 & 2 & 35.5759 & 6 & 36.1021 & 2 & 40.7669 & 2 \\
\hline 5 & 32.001 & 1 & 31.1421 & 4 & 41.0338 & 1 & 47.1787 & 0 & 48.3621 & 2 \\
\hline 6 & 30.3857 & 0 & 31.1225 & 1 & 41.5973 & 2 & 42.1372 & 0 & 41.6364 & 1 \\
\hline 7 & 45.1423 & 0 & 40.7455 & 1 & 49.6259 & 1 & 54.6775 & 1 & 63.8415 & 1 \\
\hline 8 & 31.4683 & 1 & 37.1498 & 0 & 45.3188 & 2 & 45.7499 & 0 & 44.3443 & 0 \\
\hline 9 & 36.0543 & 2 & 36.2102 & 0 & 55.653 & 2 & 55.815 & 1 & 55.6936 & 1 \\
\hline 10 & 33.9736 & 2 & 38.7658 & 1 & 43.5762 & 4 & 48.9865 & 1 & 51.8879 & 4 \\
\hline 11 & 33.538 & 2 & 35.0406 & 1 & 47.9865 & 0 & 47.3505 & 0 & 50.5594 & 2 \\
\hline 12 & 28.7978 & 3 & 29.7057 & 0 & 38.8607 & 1 & 41.8713 & 1 & 43.0599 & 1 \\
\hline 13 & 29.1463 & 3 & 28.5153 & 3 & 31.6979 & 1 & 35.7697 & 1 & 39.9714 & 2 \\
\hline 14 & 37.9305 & 6 & 34.4247 & 1 & 44.7016 & 5 & 51.5384 & 2 & 52.0856 & 0 \\
\hline 15 & 39.7701 & 2 & 35.3683 & 2 & 47.8084 & 1 & 53.6807 & 0 & 57.3783 & 0 \\
\hline 16 & 29.641 & 1 & 27.3238 & 1 & 38.0435 & 2 & 43.1819 & 1 & 45.3366 & 1 \\
\hline 17 & 33.3467 & 1 & 31.4097 & 0 & 40.0934 & 1 & 42.1258 & 0 & 48.5045 & 1 \\
\hline 18 & 31.1304 & 2 & 33.2719 & 2 & 42.1134 & 3 & 47.1551 & 0 & 48.1866 & 2 \\
\hline 19 & 36.8033 & 3 & 39.4367 & 1 & 48.6808 & 2 & 53.96 & 0 & 52.9506 & 1 \\
\hline 20 & 26.2689 & 3 & 27.1396 & 1 & 32.8871 & 4 & 37.9968 & 0 & 41.0372 & 1 \\
\hline 21 & 32.1609 & 3 & 35.226 & 0 & 44.7341 & 3 & 49.1733 & 1 & 50.0253 & 2 \\
\hline 22 & 32.4412 & 1 & 33.1535 & 0 & 41.9012 & 2 & 42.3789 & 0 & 49.717 & 0 \\
\hline 23 & 32.0395 & 0 & 35.3142 & 1 & 42.7173 & 2 & 49.5323 & 1 & 46.918 & 1 \\
\hline 24 & 30.2808 & 0 & 29.5629 & 2 & 41.3743 & 2 & 42.2825 & 2 & 51.4701 & 0 \\
\hline 25 & 38.408 & 6 & 30.8581 & 1 & 40.8181 & 4 & 46.4917 & 2 & 49.6914 & 2 \\
\hline
\end{tabular}
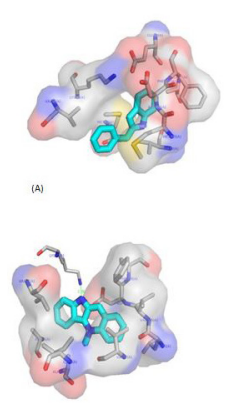

(B)

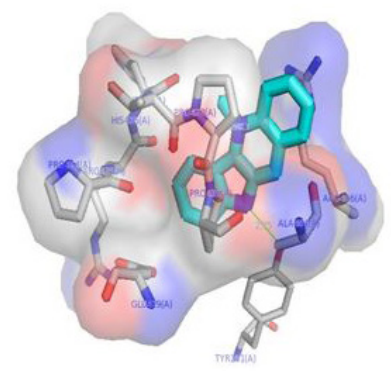

(E)
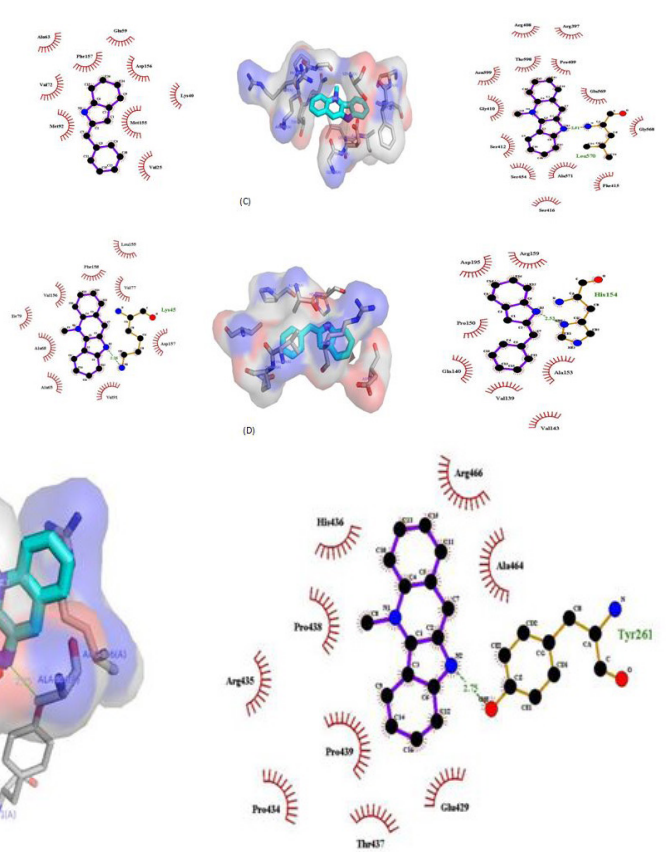

Figure 4. Ligand 7 in the binding site pocket of target proteins (A-E) where the ligand is shown in cyan and 2-D representation of the interaction of Ligand7 with target proteins $\mathrm{PknB}(\mathbf{A}), \operatorname{PknE}(\mathbf{B}), \operatorname{PstP}(\mathbf{C}), \operatorname{PknG}(\mathbf{D})$, and PbpA(E). 


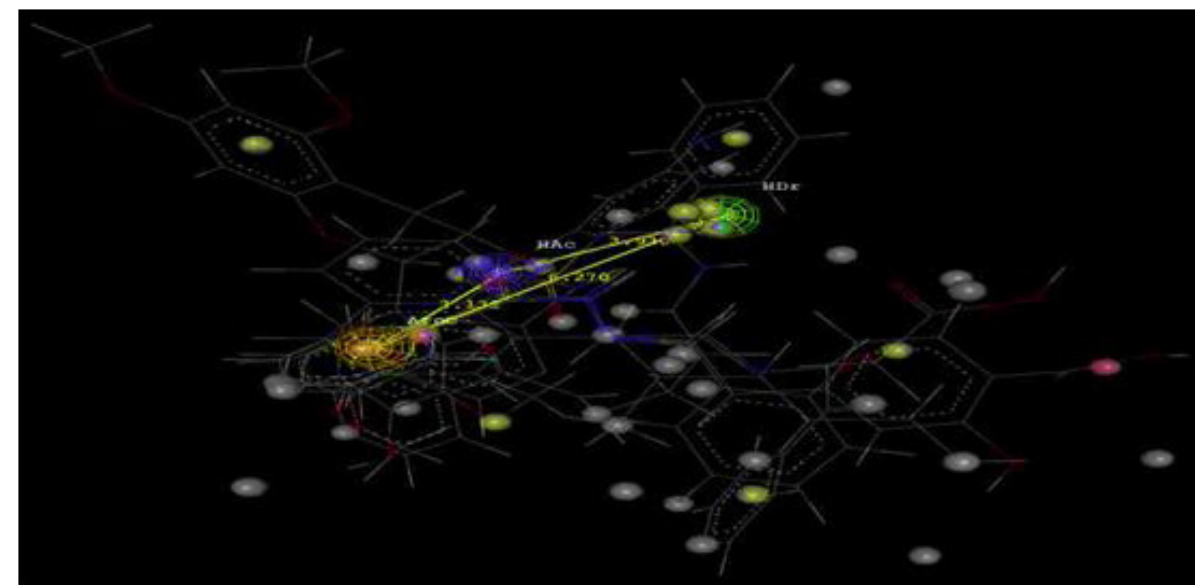

Figure 5. Superimposition of the best docked 12 ligands using ligand 10 as a reference.

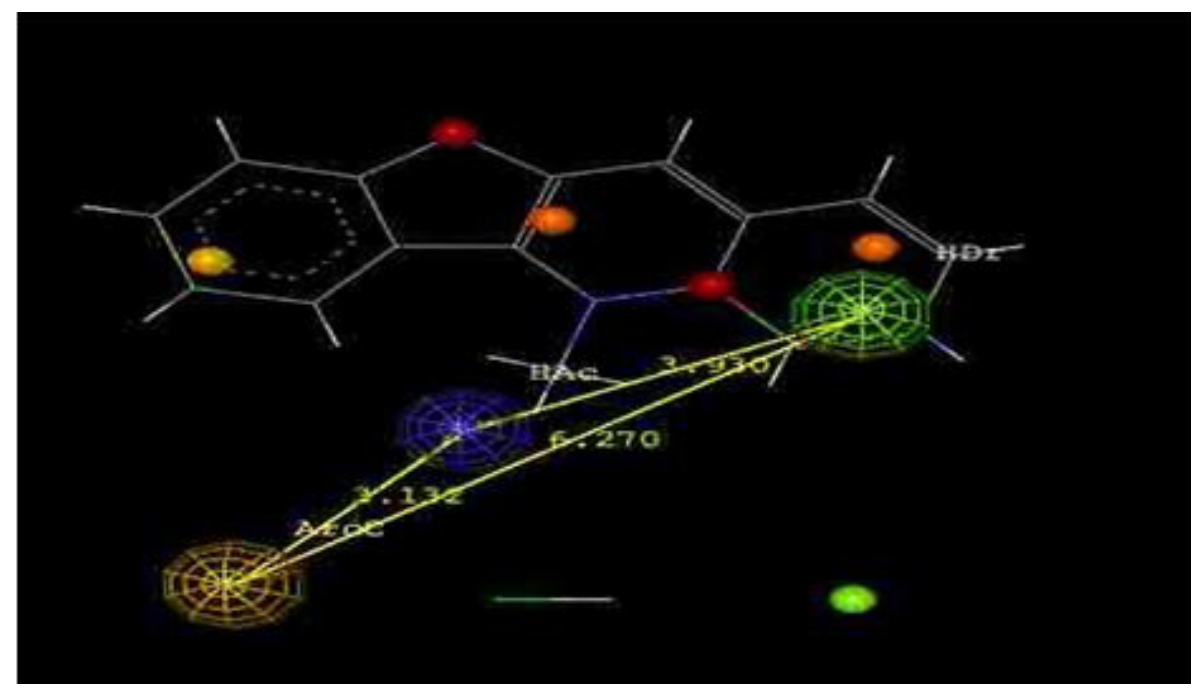

Figure 6. Pharmacophore model generated for ligand 7 (Cryptolepine $\mathrm{HCl}$ ): stick model representation of the ligand 7. Pharmacophoric regions are indicated by green (Hydrogen bond donor), blue (Hydrogen bond acceptor) and yellow spheres (Aromatic carbon) connected by lines representing distance constraints in the pharmacophore model. Small spheres in orange, yellow, and green indicate additional pharmacophore regions.

\section{Conflicts of interest}

The authors declare no conflict of interest.

\section{ACKNOWLEDGMENTS}

Research supported by the King Saud University, Deanship of Scientific Research, College of Science, Research Center. 


\section{REFERENCES}

Av-Gay Y and Everett M (2000). The eukaryotic-like Ser/Thr protein kinases of Mycobacterium tuberculosis. Trends Microbiol. 8: 238-244.

Boitel B, Ortiz-Lombardía M, Durán R, Pompeo F, et al. (2003). PknB kinase activity is regulated by phosphorylation in two Thr residues and dephosphorylation by PstP, the cognate phospho-Ser/Thr phosphatase, in Mycobacterium tuberculosis. Mol. Microbiol. 49: 1493-1508.

Camacho-Corona MR, Favela-Hernández JM, González-Santiago O, Elvira Garza-González, et al. (2009). Evaluation of some plant-derived secondary metabolites against sensitive and multidrug-resistant Mycobacterium tuberculosis. $J$. Mex. Chem. Soc. 53: 71-75.

Chauhan PM, Sunduru N and Sharma M (2010). Recent advances in the design and synthesis of heterocycles as antitubercular agents. Future Med. Chem. 2: 1469-1500.

Chen FC, Peng CF, Tsai IL and Chen IS (2005). Antitubercular constituents from the stem wood of Cinnamomum kotoense. J. Nat. Prod. 68: 1318-1323.

Chopra P, Singh B, Singh R, Vohra R, et al. (2003). Phosphoprotein phosphatase of Mycobacterium tuberculosis dephosphorylates serine-threonine kinases PknA and PknB. Biochem. Biophys. Res. Commun. 311: 112-120.

Cohen FE and Prusiner SB (1998). Pathologic conformations of prion proteins. Annu. Rev. Biochem. 67: 793-819.

Cole ST, Brosch R, Parkhill J, Garnier T, et al. (1998). Deciphering the biology of Mycobacterium tuberculosis from the complete genome sequence. Nature 393: 537-544.

Cowley S, Ko M, Pick N, Chow R, et al. (2004). The Mycobacterium tuberculosis protein serine/threonine kinase PknG is linked to cellular glutamate/glutamine levels and is important for growth in vivo. Mol. Microbiol. 52: 1691e702.

Durán R, Villarino A, Bellinzoni M, Wehenkel A, et al. (2005). Conserved autophosphorylation pattern in activation loops and juxtamembrane regions of Mycobacterium tuberculosis Ser/Thr protein kinases. Biochem. Biophys. Res. Commun. 333: 858-867.

Ehrlich P (1909). Ueber den jetzigen Stand der Chemotherapie. Ber. Dtsch. Chem. Ges. 42: 17-47.

Fernandez P, Saint-Joanis B, Barilone N, Jackson M, et al. (2006). The Ser/Thr protein kinase PknB is essential for sustaining mycobacterial growth. J. Bacteriol. 188: $7778 \mathrm{e} 84$.

Gentry EJ, Jampani HB, Keshavarz-Shokri A, Morton MD, et al. (1998). Antitubercular natural products: berberine from the roots of commercial Hydrastis canadensis powder. J. Nat. Prod. 61: 1187-1193.

Gibbons S, Fallah F and Wright CW (2003). Cryptolepine hydrochloride: a potent antimycobacterial alkaloid derived from Cryptolepis sanguinolenta. Phytother. Res. 17: 434-436.

Ginsberg AM (2008). Emerging Drugs for active tuberculosis. Semin. Respir. Crit. Care Med. 29: 552-559.

Gupta A, Kaul A, Tsolaki AG, Kishore U, et al. (2012). Mycobacterium tuberculosis: immune evasion, latency and reactivation. Immunobiology 217: 363-374.

Kang CM, Abbott DW, Park ST, Dascher CC, et al. (2005). The Mycobacterium tuberculosis serine/threonine kinases PknA and PknB: substrate identification and regulation of cell shape. Genes Dev. 19: 1692e704.

Koul A, Arnoult E, Lounis N, Guillemont J, et al. (2011). The challenges of new drug discovery for tuberculosis. Nature 469: 483-469.

Lin WY, Peng CF, Tsai IL, Chen JJ, et al. (2005). Antitubercular constituents from the roots of Engelhardia roxburghiana. Planta Med. 71: 171-175.

Loregian A, Mardsen HS and Palu G (2002). Protein-protein interactions as targets for antiviral chemotherapy. Rev. Med. Virol. 12: 239-262.

Lougheed KE, Taylor DL, Osborne SA, Bryans JS, et al. (2009). New anti-tuberculosis agents amongst known drugs. Tuberculosis 89: 364-370.

Rastogi N, Abaul J, Goh KS, Devallois A, et al. (1998). Antimycobacterial activity of chemically defined natural substances from the Caribbean flora in Guadeloupe. FEMS Immunol. Med. Microbiol. 20: 267-273.

Rogoza LN, Salakhutdinov NF and Tolstikov GA (2010). Antituberculosis activity of natural and synthetic compounds. Chem. Sustain. Dev. 18. 343-375.

Sassetti CM, Boyd DH and Rubin EJ (2003). Genes required for mycobacterial growth defined by high density mutagenesis. Mol. Microbiol. 48: 77e84.

Selkoe DJ (1998). The cell biology of beta-amyloid precursor protein and presenilin in Alzheimer's disease. Trends Cell. Biol. 8: 443-457.

Szklarczyk D, Franceschini A, Kuhn M, Simonovic M, et al. (2011). The STRING database in 2011: functional interaction networks of proteins, globally integrated and scored. Nucleic Acids Res. 39: D561-D568.

Tufariello JM, Chan J and Flynn JL (2003). Latent tuberculosis: mechanisms of host and bacillus that contribute to persistent infection. Lancet Infect. Dis. 3: 578-590. 
Tyagi SJ and Sharma D (2004). Signal transduction systems of mycobacteria with special reference to M. tuberculosis. Curr. Sci. 86: 93-102.

Walburger A, Koul A, Ferrari G, Nguyen L, et al. (2004). Protein kinase G from pathogenic mycobacteria promotes survival within macrophages. Science 304: 1800e4.

Zhang R, Ou HY and Zhang CT (2004). DEG: a database of essential genes. Nucleic Acids Res. 32: D271-D272.

Zhang Y (2005). The magic bullets and tuberculosis drug targets. Annu. Rev. Pharmacol. Toxicol. 45: 529-564.

Zvi A, Ariel N, Fulkerson J, Sadoff JC, et al. (2008). Whole genome identification of Mycobacterium tuberculosis vaccine candidates by comprehensive data mining and bioinformatic analyses. BMC Med. Genomics 1: 18 . 